\title{
Why an open access publishing cooperative can work
}

\section{A proposal for the AAA's journal portfolio}

\author{
Alberto Corsín Jiménez, John Willinsky, Dominic \\ Boyer, Giovanni DA Col, and Alex Golub
}

The American Anthropological Association (AAA) has recently announced that it will soon issue a Request for Proposals (RFP) to invite potential publishers to bid for the business of managing the association's publishing program (see Schmid 2015). The new contract would begin January 1, 2018 and likely run for the next ten years. Because the AAA is the world's largest publisher of anthropology titles (twenty-one journals and Anthropology News), this new publishing contract will shape the discipline's public image and scholarly communications for years to come. At this critical juncture we must ask: Will AAA publications spend yet another decade locked within a publisher website where only research libraries can afford to purchase them? Or can our scholarly work join the growing body of research that is publicly available and accessible as a public good? In this piece we propose a concrete, practical, and financially sustainable way that the AAA can make their publishing program open access: a cooperative model of scholarly publishing. This tailor-made design will cost the AAA nothing, and give the AAA a chance to be at the forefront of global innovation in scholarly communication. We urge the AAA to take it seriously as they think about the future of their publishing program.

Our proposal draws on the expertise of two of the world's most reputed open access advocacy organizations: the Scholarly Publishing and Academic Resources Coalition (SPARC) and the Public Knowledge Project (PKP). Both organizations 
have agreed to commit time, money, and resources to help the AAA transition towards an open access publishing ecology: SPARC is willing to carry out a financial and data analysis of the AAA's publishing program at no expense to the association, while PKP is willing to design a web tool to model the AAA's new multi-stakeholder ecology of open access publishing. The specifics of PKP and SPARC's proposal will be sent directly to the AAA, since some of the financial information is sensitive. Here, we would like to talk about the general model that we are suggesting.

\section{Cooperative publishing: The ethical, feasible model for digital scholarly communication}

When the AAA's RFP comes out, it will ask its partners to undertake something more than just submissions, copyediting, and typesetting. In our digital age, archiving, citation tracking, and social media promotion are also part of the process of scholarly communication. Because a new digital publishing medium has taken hold, the AAA has new opportunities to promote access and share content, as well as new technologies to keep track of how content circulates, how it is read and cited, how it contributes to on-going conversations and public discussions.

Our cooperative model for scholarly publishing is designed for this new world. Designed for the AAA's publishing and organizational requirements, it also seeks to build a robust and sustainable multi-stakeholder ecology of open access scholarly communications involving libraries, funding agencies, and infrastructure providers.

This model is also deeply attuned to our scholarly values because it is collaborative, communal, and cooperative. There is no reason this spirit should only prevail in libraries, laboratories, and research sites; it can and should be central to scholarly publishing as well. We have known for some time that open access is hardly sustainable when based solely on an individual journal project (see Waltham 2010). Therefore, this new openness will need to build on the collective and collaborative spirit of scholarly communication.

There is proof that this model can work. Some of the most exciting and innovative developments in the publishing world reflect the spread of this spirit to scholarly communication: HaU: Journal of Ethnographic Theory and HaU Books, the University of California Press' Collabra, the Open Library of the Humanities, Knowledge Unlatched and the Public Knowledge Project have all set out to work in cooperative partnership with a variety of stakeholders (libraries, editors, funding agencies, universities). These projects have demonstrated that it is possible to overcome the problematic assumption that there must be a wall between commercial presses and learned societies/journals, between research as a private asset and a public good, since the mid-twentieth century.

Our proposal builds on the on-going work of two recent open access datagathering initiatives and modeling exercises that have anthropology at their center:

(i) LIBRARIA (http://libraria.cc/) is a partnership of anthropology and STS learned societies and journals, the Public Knowledge Project (PKP), and the Scholarly Publishing and Academic Resources Coalition 
(SPARC) that have united to explore cooperative alternatives for scholarly publishing. To this day its members include the WennerGren Foundation (who publishes Current Anthropology), the European Association of Social Anthropologists (Social Anthropology), the Society for Cultural Anthropology (Cultural Anthropology), the Society for Social Studies of Science (Science, Technology and Human Values), the Society for Ethnographic Theory (HAU Journal and HAU Books), Anthropological Forum, Limn, Valuation Studies, and Critique of Anthropology.

(ii) The Public Knowledge Project's “Open Access Publishing Cooperative Study" (http://oa-cooperative.org/), funded by the MacArthur Foundation (2015-17), which seeks to assess the benefits and risks, the feasibility and viability, of setting up a multi-stakeholder cooperative association-among journals, societies, libraries, and funders-for scholarly publishing (see the study's principles, outlined here: http://oa-cooperative.org/coop.html). Can a self-governing co-op established among the stakeholders, the study asks, enable a move from a subscription-driven market of closed publications (of 10-12 billion USD) to a collaborative allocation of the same funding for publishing and related expenses of operating a commons committed to improving the access and quality of research and scholarship? The study's approach is to gather data, hold consultations, develop tools and platforms, and conduct co-op pilots with groups such as Libraria.

In sum, what we need now is a model for reorganizing the economy and governance of scholarly publishing, a model with open access values at its core, with a concern for greater equality, accountability, and global participation in this access across the disciplines. To that end, over the past year we have been engaged in a collaborative study and development of an alternative "cooperative" model for open access publishing. In this model, learned societies, journals, libraries, and funding agencies come together to design a sustainable open access infrastructure for a number of anthropology and related journals.

\section{Why an open access publishing cooperative is a good idea for the AAA and other stakeholders}

What, concretely, would an AAA publishing cooperative look like? In practice, the AAA would explore a multi-stakeholder cooperative association with library consortia, and possibly associated funding bodies, as well as Libraria, that was dedicated to publishing its journals on an open access basis. The cooperative will be viable financially because it will be able to attract enough partners that it would be able to produce the same or better levels of professional publishing that it currently enjoys.

The journals and societies will keep their identities and build their readership through the open access cooperative. Because they will be using the latest open source software platforms and technical developments (such as article-level metrics and common reviewer databases), their content will be widely available and will gain greater understanding of who is reading their work. Libraries will 
benefit because they will be able to escape the subscription-fee inflation spiral. ${ }^{1}$ There already many examples of libraries which have made this move: The successful Knowledge Unlatched (http://www.knowledgeunlatched.org) pilot with open access books, as well as the hundreds of libraries that are currently hosting online open access journals at no charge (e.g., University of Pittsburgh [http:// www.library.pitt.edu/publications], University of Alberta [https://ejournals.library. ualberta.ca]). Research into the economics of publishing confirms that scalable and sustainable open access alternatives to commercial publishing are feasible. ${ }^{2}$

The cooperative model can offer universities, libraries and scholars the same value for less money than a for-profit solution because the cooperative does not need to siphon off money into corporate profits. Bergstrom et al (2014: 9428) found that "In 2011, the journal-publishing divisions of Elsevier, Springer, and Wiley [the current AAA publishing partner] reported profits equal to $36 \%, 33.9 \%$, and $42 \%$, respectively, of their sales revenue." ${ }^{3}$ They conclude that "there is ample evidence that large publishers practice price discrimination and that they have been able to set prices well above average costs." Instead of reaping profits based on price discrimination, the co-op will reinvest its returns in more advanced publishing systems, new journals, and society-directed training in new methods. The co-op can also offer new levels of transparency because it is committed to openness, which means that it will be able to build trust with both the academia and the public.

The cooperative model can also transition the AAA from a subscription model to an open access model. A recent White Paper by the Max Planck Digital Library (MPDL) makes it clear that there is sufficient funding being spent on scholarly publishing to pay for open access (Schimmer et al 2015). They conclude that "under the current subscription system, a figure between EUR 3,800 and 5,000 is already being paid per research article through library subscription spending" (ibid.: 5). On the other hand, "all the available evidence ... predicted [an] APC level of well below EUR 2,000 in a purely open access scenario" (ibid.: 7). The gap makes clear that libraries are shouldering the cost of open access while commercial presses are

1. Rebecca Kennison and Lisa Norberg (2014: 8-9), in their recent White Paper on sustainable publishing for the humanities and social sciences, state: "Academic institutions pay the lion's share of the cost of funding the current scholarly communication system. These institutions pay approximately 53\% of the global publishing and distribution costs in the form of library subscriptions. They contribute another $29 \%$ in the form of the labor provided by researchers without remuneration from the publishers (e.g., peer review, voluntary editorships), and often institutions pick up the tab for the roughly $2 \%$ of 'author-side' payments."

2. For a concrete proposal see Kennison and Norberg (2014). For a global and comparative examination of library resources that would justify and enable a change in the system of payment streams for open access scholarship, see Schimmer et al (2015).

3. Exxon Mobil, comparatively, has a net profit margin of $7.31 \%$, Rio Tinto's is $13.69 \%$, even JPMorgan Chase can only claim 24.57\%. Academic labor, it turns out, is a far more lucrative platform for profit accumulation than fossil fuels, mineral resources, and international finance. For more details on the exorbitant profit margins of commercial presses, see "Academic publishing: Of goats and headaches," The Economist, May 26, 2011, http://www.economist.com/node/18744177/. 
reaping the profits. Not surprisingly, the White Paper concludes by pointing out that there is lots of space for a coordinated effort to more efficiently allocate library budgets. As they put it, "the time is ripe for the global research community to accelerate the transition to open access" (ibid.: 11).

\section{A financial and business model for an open access cooperative}

We now wish to offer a thought experiment, based on real pricing data that we have been able to obtain, outlining the scope of the business and financial margins that are in fact available to open access initiatives for modeling and developing their own projects. ${ }^{4}$ Our thought experiment is not intended to describe a working model for AAA but to illustrate the type of multi-stakeholder alliances and cooperative structures that are viable today. ${ }^{5}$

\section{Journal production costs}

1. We know that university presses (e.g., Chicago, Duke) charge standard costs for open access publishing services that are on the order of $\$ 85,000$ USD for one journal, 667 pages per year.

2. Let's say we are only talking about one journal, an imaginary Journal of Contemporary Anthropology, which publishes four issues per year at about 167 pages per issue, with each issue consisting of approximately ten research articles (seventeen pages each), or, forty articles total per year.

3. Each JCA article would then cost $\$ 2,125$ to publish open access $(\$ 85,000$ / forty articles).

These figures accord with the findings of Schimmer et al (2015: 7), who note that "all the available evidence that has been published or discussed in various reports points consistently to a predicted APC level of well below EUR 2,000 in a purely open access scenario."

4. In preparation of this model we have used data from the following sources: Kennison and Norberg 2014; Schimmer et al 2015; Morrison et al 2015; the HaU Network of Ethnographic Theory model: http://www.haujournal.org/index.php/hau/pages/view/ hau-net; and The Open Library of the Humanities Model. https://about.openlibhums. org/wp-content/uploads/2013/01/2015-Summary-of-OLH.pdf.

5. We are aware of the limitations of our projections. Our exercise is not meant to model a real case scenario. We simply want to outline the contours of what a novel system of payment streams could do. A proper modeling exercise would require data on actual production costs for each journal; subscription lists for each library; cross-subsidies between journals; operational revenues and costs for each learned society (in the event that journal publishing subsidize a society's operations); offsetting arrangements between libraries and publishers; etc. It is this sort of data that the PKP-MacArthur Open Access Publishing Cooperative Study is compiling and analyzing. It is such a multistakeholder modeling exercise that we would like to see the AAA join. 


\section{Library acquisition funds}

In their policy paper for the Max Planck Digital Library, Schimmer et al (2015: 5) have calculated that "under the current subscription system, a figure between EUR 3,800 and 5,000 is already being paid per research article through library subscription spending."

Let's say, then, that libraries are currently paying EUR 3,800 (\$4,290 USD) per anthropological research article. In the case of the JCA, which publishes forty articles per year, that would amount to $\$ 171,600$ per volume. This is the total cost that a commercial publisher would seek to recover from libraries' subscription fees. And please note that these are just subscription costs for a restricted access journal. If the JCA were to be made open access via the model preferred by commercial publishers, universities would additionally have to pay APCs if they wished for their faculty's publications to be ungated.

\section{Difference between open access publication and library acquisitions}

So, it is already clear that there is a substantial gap between what it would cost for a university press to produce a journal like the JCA in an open access model $(\$ 85,000)$ and what it would cost libraries tied to a subscription model to purchase access to the same journal in the conventional restricted access model $(\$ 171,600)$.

Now let's scale up our model into a portfolio of journals including the twentytwo AAA journals (inclusive of Anthropology News) and the eight journals currently represented in Libraria.

Working with a university press, it would cost $\$ 2,550,000$ to publish this portfolio of thirty journals open access. Comparatively, we know from the data in Schimmer et al that libraries subscription fees would amount to $\$ 5,148,000$ for the same portfolio in the conventional model.

\section{A cooperative model}

Thus far, we have just been working with the standard open access publishing costs for a university press. However, we know that a cooperative structure would be in a position to pool resources, labor, infrastructures, and technologies in a digital environment.

Ubiquity Press, for example, who are running the publishing platform of the Open Library of the Humanities, has APCs of only \$500, roughly a quarter of the university press rate. But let's keep our assumptions conservative and say that the co-op would be in a position to sustain the cost of open access publishing at $\$ 60,000$ per journal per year.

That would be $\$ 1,800,000$ for the whole portfolio of thirty journals. (Reminder: libraries would be spending a total of $\$ 5,148,000$ on subscription fees for a similar portfolio.)

\section{Revenue for learned societies}

We are further aware that commercial presses such as Wiley-Blackwell guarantee a stream of revenue for learned societies such as the AAA. These figures are not publicly available but let us suppose that the AAA is currently getting $\$ 500,000$ per year from Wiley, which it uses to provide vital services to develop the profession and its scholarship. 
And since it wouldn't just be the AAA within our portfolio, we should again be conservative and set aside $\$ 1,000,000$ per year for general governance costs.

Therefore, the total operational costs of the cooperative (publishing + governance) would amount to $\$ 2,800,000$, still far less than the $\$ 5,148,000$ that the conventional model costs.

The surprising conclusion is that the cooperative model could provide a larger margin of revenues for learned societies, while making scholarly communication fully open access.

\section{Library partnership subsidies}

Since libraries would join the cooperative as partners, at this point we would be asking a consortia of libraries to use their acquisition funds to support the infrastructure of the co-op, rather than simply purchasing journals. We follow here well-established models such as those of the Open Library of the Humanities or SCOAP $3 .^{6}$

Let us say that we managed to get 400 libraries worldwide to join the cooperative, again a quite conservative estimate: $\$ 2,800,000 / 400=\$ 7,000$ per library subsidy. Libraries would each have to contribute $\$ 7,000$ to the cooperative on an annual basis. That would break down to $\$ 234$ per title, approximately $\$ 5.80$ per article.

For $\$ 5.80$ per article, libraries would be able to liberate scholarly communications in anthropology. And it would make very good financial sense for libraries given that APCs run to $\$ 3,000$ (e.g., Wiley-Blackwell) for one of their faculty members or grad students to publish a single open access article.

\section{What should happen next?}

The AAA is in a position to lead in the transition from the closed world of exclusive subscription access to a far more open world of access to anthropological research and scholarship. It could not only advance a global intellectual commons through its participation in a cooperative association dedicated to the financing and governance of that commons, but it also has the means of studying the processes and forms that this development is taking on many fronts. The AAA's Request for Proposals offers us all the opportunity to consider whether there is not a better model for sharing the work that engages us in the study and understanding of humankind.

"The time is ripe," as Schimmer et al (2015: 11) put it, but it will take collective action on the part of AAA's leadership and membership to embrace the unique and historic opportunity that the termination of our contract with Wiley-Blackwell opens before us. Importantly, the AAA is not alone in this challenge. SPARC, PKP, and Libraria have all confirmed their willingness to support and accompany the AAA in its transition to a new model. We, therefore, hereby make a call for a broad membership participation and inquiry, including section leaders and journals' editors, into an alternative open access global cooperative model. It is not the time to

6. See https://www.openlibhums.org/ and http://scoap3.org/. 
ask publishers what they can do for us. It is time to ask what we can do for a new ecology of scholarly communications.

\section{Acknowledgments}

The authors wish to express their thanks to Marisol de la Cadena, Raym Crow, John Hartigan, Chris Kelty, and Marcel LaFlamme for their very valuable feedback in the course of writing this text.

\section{References}

Bergstrom, Theodore C., Paul N. Courant, R. Preston McAfee, and Michael A. Williams. 2014. "Evaluating big deal journal bundles." Proceedings of the National Academy of Sciences 111 (26): 9425-30. http://www.pnas.org/content/111/26/9425.full.pdf.

Kennison, Rebecca, and Lisa Norberg. 2014. "A scalable and sustainable approach to open access publishing and archiving for humanities and social sciences: A white paper. $\mathrm{K} \mid \mathrm{N}$ Consultants.

http://knconsultants.org/toward-a-sustainable-approach-to-open-access-publishingand-archiving/.

Morrison, Heather, Jihane Salhab, Alexis Calvé-Genest, and Tony Horava. 2015. "Open access article processing charges: DOAJ Survey May 2014." Publications 3: 1-16. http://www.mdpi.com/2304-6775/3/1/1.

Schimmer, Ralf, Kai Karin Geschuhn, and Andreas Vogler. 2015. "Disrupting the subscription journals' business model for the necessary large-scale transformation to open access." Max Planck Digital Library Policy White Paper. http://dx.doi.org/10.17617/1.3.

Schmid, Oona. 2015. “AAA’s publishing partnership.” Anthropology News, http://www.anthropology-news.org/index.php/2015/09/23/aaas-publishing-partnership/.

Waltham, Mary. 2010. “The future of scholarly journal publishing among social science and humanities associations: Report on a study funded by a planning grant from the Andrew W. Mellon Foundation." Journal of Scholarly Publishing 41 (3): 257-324. http://dx.doi.org/10.3138/jsp.41.3.257. 